\title{
Professor Jacinto Monteiro 1949 - 2020
}

\section{Paulo Rego ${ }^{1}$}

Published online: 21 July 2020

(C) SICOT aisbl 2020

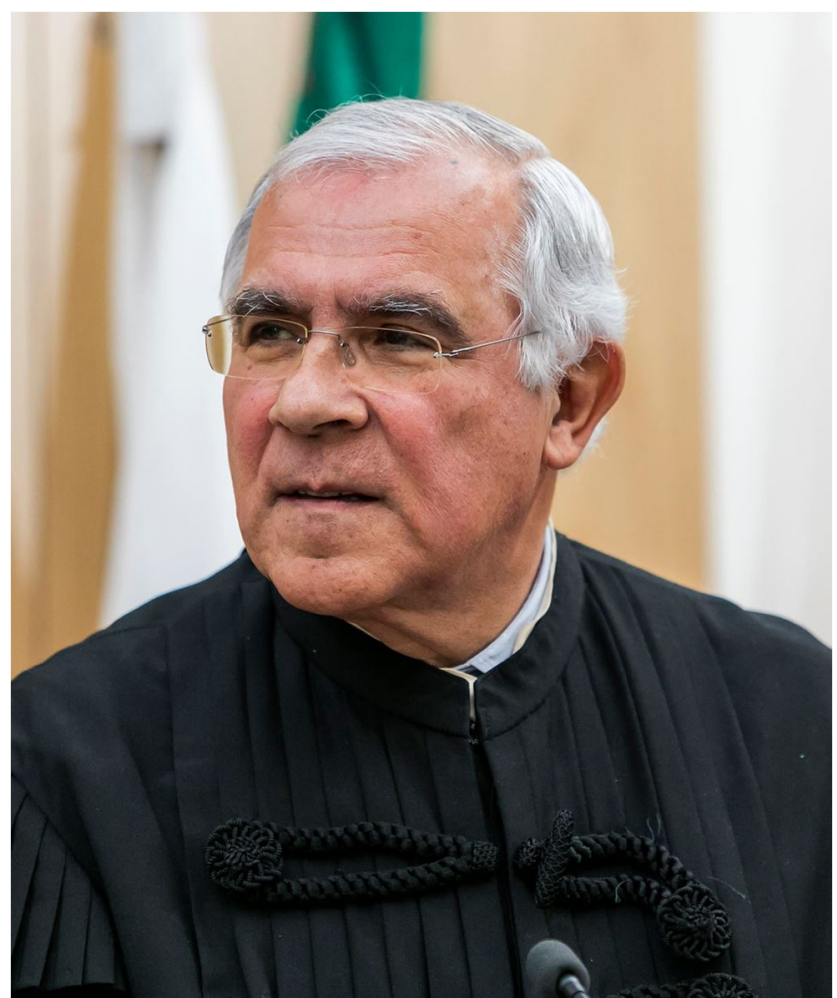

Dear colleagues it is with deep sadness that we share with you a few thoughts about Professor Jacinto Monteiro live and work. He passed away last 16th of May 2020 after a long year fighting an unfair battle with the disease.

Back into the nineties' I can still remember very well one of Professor Monteiro brilliant classes about upper limb fractures that I had the privilege to assist as a medical student. Probably my journey into orthopaedic surgery began that day, after the

Paulo Rego

pauloamaralrego@gmail.com

1 Orthopaedic Department, Hospital da Luz / Lisbon University, Lisbon, Portugal perfect understanding he gave us on upper limb biomechanics and the rationale about surgical treatment approach for elbow fractures. A very complex topic made very simple and easy to understand through his words. Later, I was a resident and a young attending orthopaedic surgeon in his department. Along my entire career, I have always felt him as a mentor, a protector and an enthusiast of serious scientific based innovation in orthopaedic surgery.

Professor Monteiro was born in Ourique, a small town in Alentejo, where he concluded his basic Education. After finishing his medical studies in Lisbon University (Santa Maria Hospital) he became a resident in orthopaedic surgery in the year of 1978, Professor in Orthopaedic Surgery in 1993 and Head of Department in 2001.

Throughout his brilliant career he defended important ideals for the practice of medicine and surgery. He always listed as first priorities patient comprehensive care and the quality of the surgical procedure over the simplistic version of the numbers for economic reasons, unfortunately very fashionable today.

He trained dozens of residents and young attending surgeons over the years and was always available to support them in all aspects, both personal and professional. He pioneered shoulder surgery in Portugal, being one of the first to perform shoulder arthroscopy and arthroplasty and building the foundations for the first department dedicated to shoulder and elbow surgery. He was also the founder of the Portuguese Shoulder and Elbow Section of the Portuguese Orthopaedic and Traumatology Society, that has later evolved to the current Portuguese Shoulder and Elbow Society. He was also President of the Portuguese Society of Orthopaedics and Traumatology, President of the Portuguese Society of Osteoporosis and Metabolic Bone Diseases and a prominent member of the National Legal Medical Council. Professor Monteiro was a well-known and familiar personality within the SICOT, chairman of the Portuguese Delegation and Chairman of the Shoulder and Elbow Scientific chapter during several SICOT international meetings and world Congresses. 
Professor Monteiro, throughout the years taught generations of medical students and encouraged colleagues who worked with him to pursue academic challenges and invest in clinical research. In 2001 he became full professor in orthopaedics in the University of Lisbon. Very active in his academic career, he supervised and was member of the jury of many doctoral and aggregation theses in his own institution and in many others, across the country.

Besides teaching Orthopaedic Surgery, he was also professor of Science of Biomaterials at the Technical University of Lisbon to biomedical engineering students. All this activity stands for his definition of continuing medical education: "The cult of the scientific spirit is supported by the sagacity of those who have found the daily acquisition of knowledge and experience, as the trigger to awake the desire to evolve, learning from mistakes, improving skills and correcting attitudes".

Professor Monteiro was also a distinguished member of several international associations like the Société Internationale de Chirurgie Orthopédique et de Traumatologie (SICOT), the British Orthopaedic Association, the European Society for Surgery of the Shoulder and the Elbow (ESSSE - SECEC), AO Alumni Association (AOAA), among others. In ESSSE he had a relevant role as a Portuguese deputy, part of the Membership Committee and as president of the SECEC 2005 congress that took place in Lisbon. Since 2005 he became an AO trustee and was very active promoting and organizing educational events across Europe and America. He was also part of the EBOT Examiner's faculty (European Board of Orthopaedics and Traumatology) and a reviewer of the Journal of Shoulder and Elbow Surgery.

Professor Monteiro, a dedicated husband, father and grandfather, said many times, "Our family support should be rated as the most significant impact factor in our carriers as surgeons and academics".

It is very difficult to resume in a few words all the richness of his professional, academic and personal live and all the challenges he managed to overcome. Even near the end his words where of confidence and hope: "We are facing many challenges, some of them not so easy, some of them not so fair for us, surgeons. However, if we remain focused in helping our patients, it will be very easy to keep improving ourselves and overcome difficulties."

He passed away last 16th of May 2020 at the age of 70 and his legacy will persist in many of us.

Publisher's note Springer Nature remains neutral with regard to jurisdictional claims in published maps and institutional affiliations. 